\title{
The impact of health services' waste to public health and to the environment
}

\author{
H. M. P. Ramos ${ }^{1}$, V. R. N. Cruvinel ${ }^{1}$ \& D. Galato ${ }^{2}$ \\ ${ }^{1}$ Department of Public Health, Faculty of Ceilândia, \\ University of Brasilia, Brazil \\ ${ }^{2}$ Pharmacy Course, Technology in Health Program, \\ Faculty of Ceilândia, University of Brasilia, Brazil
}

\begin{abstract}
The risks caused by the disposal of healthcare waste have gained great importance for the scientific community, for when discarded inadequately the waste represent potential risks for both public health and the environment. In this context it is worth noting the risks conferred to the health of scavenging workers, public health and the environment. Studies show that disposal of medicine into the common garbage or the sewage contaminates the soil and water resources. The present work aims to analyze the risks of selective collection pickers to the residues of healthcare waste and the risks that these represent for public health and the environment. This is a cross-sectional descriptive study with a quantitative approach. Interviews were conducted through a questionnaire applied to 61 workers of the Pre-Cooperative Associations of Collectors of Solid Waste and Recycle Life. The collected data has been tabulated and analyzed in a descriptive form. The results of this study show a prevalence of $51.0 \%$ of women working in associations; $36.0 \%$ of respondents aged between 30 and $39,42.6 \%$ have worked for over 10 years in the occupation of collector and $81.0 \%$ make use of personal protective equipment. Of the respondents, $23.0 \%$ had experienced some kind of accident with healthcare waste; $95.1 \%$ say they often find drugs in the workplace and $86.9 \%$ of these are medical waste. It concludes that workers are exposed to risks due to the improper disposal of waste from healthcare services. Therefore, it is necessary to strengthen strategies to raise
\end{abstract}


awareness about the proper disposal of medicines and medical waste and incorporate existing laws into the management of such waste produced in households.

Keywords: medical waste, occupational health, sewers collectors, environmental health.

\section{Introduction}

The disposing of waste has huge environmental impacts and can cause serious problems to public health especially for people who work with it. Some people consider the waste as something that has no more value or use. To others, named as waste pickers, scavengers or sewers collectors, garbage is their only source of income. While the population discards the waste as no longer useful, waste pickers aim to transform the material into a livelihood for survival [1]. It is estimated that in Brazil there are about 800,000 waste pickers, with 30,000 of them organized into cooperatives. In 2012 they accounted for $18 \%$ of the waste separated for recycling in Brazil [2]. In Brasilia, the capital of Brazil, there are 34 institutions working with recycled materials with the collaboration of approximately 2,362 workers of selective collection, which accounts for the recovery by collection or by organic waste composting process of about 75,000 tons of solid waste in 2015 [3].

Despite doing an extremely important job for both society and the environment the selective collection workers are exposed in their work process to different types of occupational hazards: physical, chemical, mechanical, ergonomic, biological and social. Among the different risks cited, the biological risk deserves more attention as it may be responsible for diseases that affect the intestinal tract caused by [Ascaris lumbricoides, Entamoeba coli, Schistosoma mansoni]; the virus that causes hepatitis [mainly type B], and the virus that causes AIDS [4]. Thus this waste requires special care because it is classified as hazardous waste as a potential source of contamination and spread of diseases.

Health Waste (HW) are residues generated in any establishment that provides healthcare services of human or animal origin. These residues are classified into five groups in accordance with Resolution RDC no. 306 of the ANVISA and Resolution no. 358 of the CONAMA, separated in accordance with their degree of danger: Group A: residues that present a risk to public health and the environment due to the presence of biological agents; Group B: residues that present a risk to public health and the environment due its physical, chemical and physicist-chemistries characteristics; Group C: radioactive residues or contaminated with radionuclides; Group D: all other residues that do not match the previously described groups and Group E are the residues of sharp devices. These HW represent a small parcel around $1 \%$ to $3 \%$ of the total of the urban solid residues. This number represents a small amount if compared to other types of residues, the great concern is the inadequate segregation that can contaminate other residues that were not contaminated before and the portion generated in the residues that are not accounted for [7]. 
In addition to the HW presenting risks to the quality of life of scavenging workers it has also become a major environmental problem, as the high amount of these medicines being deposited incorrectly in the ground is directly related to the contamination of the water resources. In addition to soil and water contamination, studies show that some microorganisms are showing resistance to drugs, since bacteria can and often makes changes in their genetic material, as they acquire resistance [8].

Currently in Brazil the standardization of technical guidelines regarding the mandatory pre-treatment of infectious fractions of HW and pharmaceuticals before their final disposal are guided by agencies of sanitary and ambient factors surveillance that act in the preservation of the public health and the environment. However, the management of these residues has not been adopted integrally, in its stages of execution, for the services of health and state and municipal management systems. Furthermore, there is still no established collecting practice of HW discarded by the population. These are often made in the regular waste or in the public sewer system, having thus conferred risks to public health affecting the quality of life and the environment. The impacts caused by the incorrect discarding of HW have already been studied by the scientific community, since the disposal of these in inadequate places allows for the transmission of diseases to humans and pollution of the environment. Thus the work aims to analyze the risks of the exposition of the residues of health for the pickers of selective collecting and the risks that these represent to public health and the environment.

\section{Methodology}

This present study is a descriptive cross-sectional epidemiologic study with a quantitative approach. The main data collection instruments were made through observations in the field and semi-structured interviews guided by questionnaire surveys divided into three stages, consisting of addressing socioeconomic factors, health hazards and accidents, damage to the environment and the risks to health in the misuse of drugs and needles found in the trash.

Data collection was conducted from November 2014 to early March 2015 in the Recycle Association Life and Pre-Cooperative Association of Solid Waste Pickers [APCORC] both located in the administrative region of Ceilândia - DF. Sixty-one solid waste pickers were interviewed by scholarship students and academic volunteers from the extension project 'Stop, Think, Dispose' from the University of Brasilia, Campus Ceilândia. These examiners were calibrated through meetings with the groups of students and there was a questionnaire validated in $10 \%$ of the samples that were later dropped.

All workers from the two associations were invited to participate in this study. The data obtained from the interviews were tabulated and analyzed using the Epidata $^{\circledR}$ software, available for free through the website epidata. The questions and data obtained through the questionnaire were analyzed using descriptive statistics, and nominal variables presented in absolute numbers and proportions and numeric variables in measures of dispersal and central tendency. 
The analysis of data was performed in the Statistical Package of Social Science [SPSS] 20.0 adopting the descriptive statistics, with nominal variables presented in absolute numbers and proportions and numeric variables in measures of central tendency [mean and median] and dispersion [deviation pattern].

This research was linked to the academic extension project at the University of Brasilia Campus Ceilândia 'Stop, Think, Discard: a multidisciplinary approach to dialogue among the university, the community and the waste pickers of Ceilândia - DF'. With acceptance of the Ethics Committee for Health Research, Campus of the University of Brasilia - UnB, followed by the Certificate Presentation to Ethics Assessment obtaining approval under the number of 427,624 .

\section{Results and discussion}

With the analysis of the results the prevalence of women representing $59 \%$ compared to men who accounted for $41 \%$ was revealed. This prevalence of women working in cooperatives is pointed in different studies [9-11]. Hoefel et al. [12] found that nearly $85 \%$ of women garbage workers interviewed in the Structural Landfill Cooperative - DF are in the reproductive age, up to 49 years old. In this study $72.2 \%$ of the women are in the same age group.

About the age of the interviewees, 36.1\% are 30-39 years old. Similar results were found in studies conducted by Gonçalves et al. [13] and Kirchener et al. [14] that prevailed pickers aged 25-45 years. Regarding the level of education, it is observed that $65.56 \%$ of respondents had not completed even primary school. These data corroborate with the research previously carried out by Alencar et al. [1] and Schmitt and Esteves [15] who noted in both studies that the low educational level of scavengers contribute to the process of social exclusion and interferes directly in the social determinants of health.

With regard to the link with associations to most collectors, $78.1 \%$ claim to be linked. These environments according to Castilhos Junior et al. [16] represent an opportunity to the collectors to organize and have a representative, thus contributing to the increase in income, social status and self-esteem. $42.62 \%$ of the interviewees work with scavenging for more than 10 years between 5 and 6 times a week, ranging from 5 to 9 hours a day totaling $88.52 \%$ of interviewees. Similar data are indicated in studies by Castilhos Junior et al. [16], Alencar et al. [1] and Hoefel et al. [12]

Regarding the HW, $95.1 \%$ of the workers say they often find drugs in the garbage treadmills in bottles, half a pack or even boxes without apparent use and 89.9\% have observed medical materials such as: syringes, needles, blood bags, woven with secretions, medicines and anatomical pieces of human and animal origin (indicated in figure 1). Compatible results are pointed out in the study by Amante [11] at the dump of city Estrutural - DF.

For Ferreira and Angels [4] pathogenic micro-organisms are not only present in waste generated in establishments that provide health services. Home environments are responsible for a large amount of waste that may contain 
disease-causing agents in the intestinal tract and cause hepatitis [mainly type B]. These are potential risks because they have the ability to resist an adverse environment.

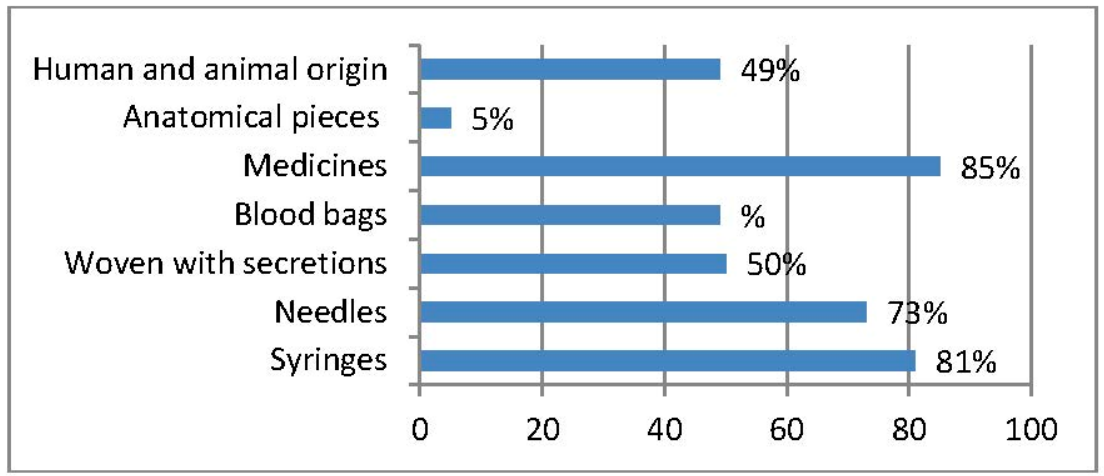

Figure 1: State of residues found in trash.

To Zanon [17], the temporary presence of live primary pathogens in domestic and hospital waste does not mean that such waste can pass them, since access to the host depends on the existence of a transmission path and a gateway. The potential risk of direct transmission of infectious diseases by any type of solid residue depends on the presence of an infectious agent, its survivability in the trash and the possibility of transmission of garbage into a susceptible host.

The Brazilian Regulatory Standard [BRS] No. 6 provides for the use of single protection equipment [SPE]. The use of these is key for protection against the risks that threaten safety and occupational health. Regarding the use of such equipment, it was found that most collectors $(88.5 \%)$ said they make use of any type of equipment while performing the work.

The types of SPE most cited are gloves, boots and masks (listed in figure 2). These data corroborate the study by Castilhos Junior et al. [16]. According to the

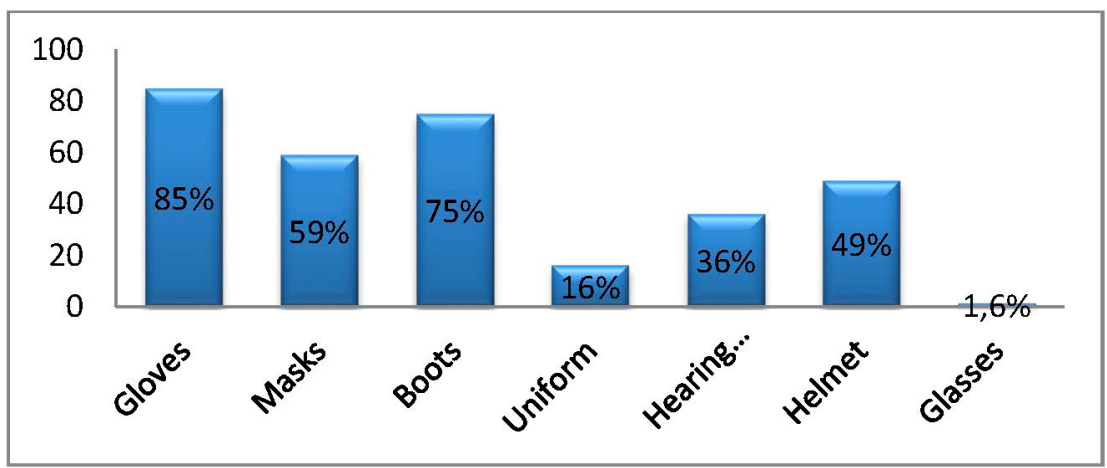

Figure 2: Single frequency usage of protective equipment by the collectors in the associations. 
author, the use of some equipment is sometimes not adopted by workers due to heat or relative inflexibility provided by them. For some workers, using gloves does not protect against cuts, they are considered brittle and therefore they tear easily. Moreover, they hamper the use in the separation process of materials which generates greater discomfort to the job being done.

Table 1 presents data relating to accidents caused by medical waste. Among respondents $23 \%[\mathrm{n}=14]$ had experienced some kind of accident when handling the waste. Several authors argue that the sharp objects are responsible for most accidents in cooperatives, as well as being the main risk agent for these workers $[10,18-21]$. Only $43 \%[n=6]$ of the workers who had accidents went to the health service for guidance. According to them, the fear of contracting diseases, contracting AIDS, to die or be unable to work is important and reflects the vulnerability in which they find themselves. In a survey conducted by Vacari et $a l$. [20] the measures taken by the pickers against suffering injuries from sharp residues looking for the clinic, hospital, rubbing alcohol on site, wash the affected area and self-medicate, some mentioned by respondents.

Table 1: Accident frequency with waste health services in Recycle Associations Life and APCORC Administrative Region of Ceilândia $-\mathrm{DF}$.

\begin{tabular}{lcc}
\hline & \multicolumn{2}{c}{ Group } \\
Accidents & N & \\
Yes & & \\
No & 14 & 23.00 \\
Did not inform & 39 & 63.90 \\
& 08 & 13.10 \\
Looked for help & & \\
Public hospital & & \\
Health center & 03 & 4.9 \\
Did not look for help & 03 & 4.9 \\
Did not inform & 06 & 9.9 \\
& 49 & 80.3 \\
\hline
\end{tabular}

Regarding the notion of danger facing most workers, $90.2 \%$ consider the medical waste to be hazardous to health and $9.8 \%$ reported not knowing the risks. Of those who responded affirmatively, the risks reported by them were: $37.5 \%$ related to communicable diseases such as HIV, HBV, Syphilis, $23 \%$ contamination, tetanus $6.5 \%$ and $33 \%$ other [bacteria, viruses, life-threatening and leading to death]. Similar data were found in the study by Amate [11] showing concern of collectors about the potential risk of contamination by a human immunodeficiency virus.

Many collectors show concern with regard to health and the possible transmission of disease by handling the waste, but do not make use of single protection equipment [SPE] by considering a distant problem. For several 
reasons, the knowledge of the danger, for these individuals, it is not enough to change their habits and attitudes in preventive actions [21].

When asked about the possible use of drugs found in the trash (figure 3), it is observed that there is a discrepancy in the reported data. No respondent answered that had ingested medication found in the trash when asked. The shame about saying who had made use of a drug found in the trash can be a possible explanation for this result. This behavior may be related to the vulnerability which workers face and the lack of knowledge of the risks that their use can affect their health and quality of life. Corroborating this statement - in a survey of collectors in Rio Grande, it was revealed that $41 \%$ of workers found drugs in the trash and separate them in order to use later. They did not think about the health-damaging residues [22].
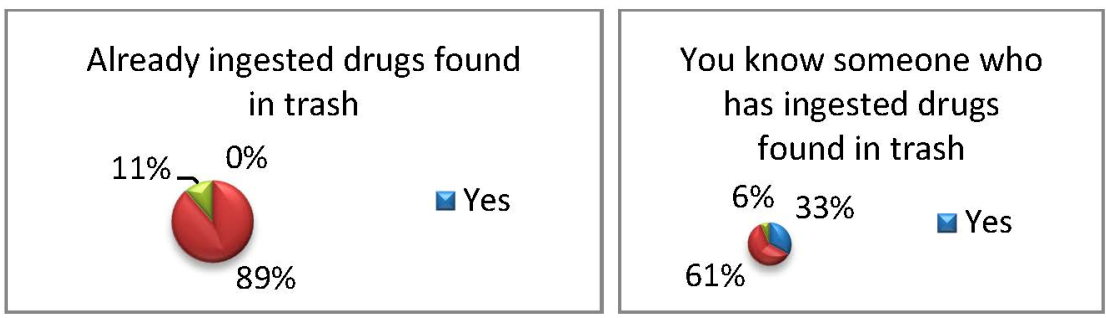

Figure 3: Ingestion of drugs found in the trash by waste pickers from the associations.

In relation to the risks related to human health in the use of drugs found in the garbage, $68.9 \%$ reported knowing the risks, including some of them reported this action can harm to health and contaminate the person. When asked about the risks to the environment caused by drugs $32.2 \%$ reported knowing about it. Among them were cited pollution of the soil, planting contamination and the delay in the process of decomposition. The disposal of chemical waste, in particular medicines, has aroused great interest in the scientific community as the disposal of these compounds in the environment is a dangerous act and presents health risks to scavengers. In studies conducted by Ueda et al. [23], Bueno et al. [24] and Duim et al. [25] was noted that the sites that are most used by the population to dispose of pharmaceutical waste is household wastes and sewage network .

The large amount of drugs found by scavengers in the present study may also be related to the lack of population on the management and proper disposal of such waste. The regulations of the National Health Surveillance Agency [ANVISA] - established by RDC No. 306/04 responsibility of handling and proper disposal of this waste, but leaves a gap in the legislation as the remains of medicines and RS generated in home environments. In this context more actions involving education and public awareness are required regarding to the correct disposal of medical waste. It is also important that there is a political will of the leaders to enforce the rules and existing health recommendations, supporting 
those who are already aware of the importance of adopting this behavior and finding ways for the understanding of those who do not know yet.

Regarding the contribution to the social security $81.9 \%$ reported not to pay it and in some cases do not understand the importance of this contribution to their future, or even, in situations of need. This is an important finding and brings the issue of vulnerability, both by the harsh work and the lack of coverage in the event of damage to health and inability to work. Social security is a social insurance that guarantees to policyholders many ways of protection not only of old age, but also in cases of incapacity for work [26].

For the IPEA [27] there are two reasons that contribute to the low contribution to the social security by collectors. Low income compromising the ability to contribute and the lack of knowledge about the benefits of Social Security. These findings point to the need for programs that encourage these workers to contribute, either through special forms of contribution to this sector, which is constantly on the agenda of the National Movement demands of Solid Waste Pickers, whether through greater awareness of the benefits that social security coverage provides, especially in an activity subject to many physical and psychological risks like this.

\section{Conclusions}

The discard of HW has become one of the major global challenges, the growth of the population and of the chronic diseases elevate the quantity of medication use and other inputs of health which subsequently will be discarded. The responsible authorities for the maintenance and preservation of the environment and quality of life of the population has been mobilized to make laws which minimise the risks caused by these residues, however has if shown on inoperative and ineffective, since they leave important gaps with respect to disposal of HW produced in indoors that directly affect the work of the pickers and public health. In this sense it is necessary to strengthen the current policies that address the theme of HW, sensitizing the population to the proper disposal of such waste including medicinal products which are used by this group of workers in addition to contaminate the environment.

\section{References}

[1] Alencar, M. C. B., Cardoso, C. C., Antunes, M. C. Working conditions and symptoms related to the health of waste pickers in Curitiba. Rev. Tuesday. Max. Univ. São Paulo, v. 20, no. 1, pp. 36-42, 2009.

[2] Cempre. Historical context: the evolution of recyclable prospects in Brazil. Review. pp. 1-24, 2013.

[3] SLU Government Solid Waste Diagnosis of the Federal District. Urban sanitation services. Report 2014. March 2015. Available in: http://www.df.gov.br/images/agencia_brasilia/2015/04-ABRIL/Relatorio_ diagnostico_residuos_solidos_SLU_2014.pdf Accessed on 02 February 2015. 
[4] Ferreira, J. A., Angels, L. A. Collective and occupational health aspects associated with the management of municipal solid waste. Public Health documents. Rio de Janeiro, v. 17, no. 3, pp. 689-696, 2001.

[5] Lazzari, M. A. Urban garbage collectors of Dourados and their perception about the biological risks in their work process. Science \& Public Health. IX Congress of Public Health of Oct. 314 Nov. 2009.

[6] Moraes, M. V. G. Occupational Diseases. Agents: Physical, chemical, biological, ergonomic. São Paulo, 2010.

[7] Maders, G. R., Castro, H. S. The Management of Health Services Waste and principles of environmental law with emphasis on intergenerational equity. Planet Amazon: International Journal of Environmental Law and Public Policy, Macapa No 2, pp. 11-20, 2010.

[8] Bila, D. M., Dezotti, M. Fármacos no meio ambiente. Quim. Nova, Vol. 26, No. 4, pp. 523-530, 2003.

[9] Soares D. L. C. Analysis of occupational hazards and accidents in waste pickers in Ceilândia Cooperatives - DF. Monograph. Ceilândia, 2014 p. 63.

[10] Ferreira, R. G. P. S. Profile of Collectors of solid waste Ceilândia - DF: a look at the social and environmental determinants of health. Monograph. Ceilândia, 2013 p. 75.

[11] Amate, E. M. Where is the health residue of the Federal District? The prospect of waste pickers. Masters dissertation. University of Brasilia. 2013.

[12] Hoefel, M. G. et al. Accidents at work and living conditions of recyclable waste pickers in landfill Federal District. Rev. Brazilian Epidemiology. 2013.

[13] Gonçalves et al. Life in the trash: a case study on the collectors of recyclable materials in the city of Ipameri, GO. Holos, Year 29, Vol 2, 2013.

[14] Kirchener et al. Metal Perceptions and profile of collectors of recyclable materials in the city of RS. Journal of Management and Regional Development. Taubaté, Brazil. G \& DR v. 5, no. 3, pp. 221-232, 2009.

[15] Schmitt, J. M. P., Esteves, A. B. S. Working conditions of Recyclable Materials of the Dump in the Capital of Brazil. In: Challenges for Public and Private Sector Industrial Relations and Unions in times of Crisis and Austerity CIES-ISTEC 5 to 7 September 2012, Lisbon, Portugal. Annals. Lisbon, Portugal.

[16] Castilhos Junior et al. Pickers of recyclable materials: analysis of working conditions and operational infrastructure in the South, Southeast and Northeast of Brazil. Science \& Public Health, 18 [11]: 3115-3124, 2013.

[17] Zanon, U. Risks Attributed to Infectious Medical Waste Sanitary Epidemiological Reality or Fiction? Brazilian Journal of the Society of Tropical Medicine 23 [3]: 163-170, 1990.

[18] Silva, M. C. Work and health of waste pickers in a city in southern Brazil. Doctoral Thesis. Pellets, 2006. Available at: http://www.ufpel.edu.br/tede/ tde_busca/arquivo.php?codArquivo=520 Acessado em: 24 mar. 2015. 
[19] Porto, M. F. S. et al. Trash, work and health: a case study of garbage pickers at the metropolitan landfill in Rio de Janeiro, Brazil. Cad. of Public Health, vol. 20, no. 6, pp. 1503-1514, 2004.

[20] Vacari, L. M. et al. Working conditions of waste pickers in Guabirotuba region. 29th Seminar of University Extension in the Southern Region, 2011.

[21] Cavalcante, S., Franco, M. F. Job hazard: perception of risk to health in the Dump the collectors of Jangurussu. Rev. Mal-Being Subj. [online]. 2007, vol. 7, n. 1, pp. 211-231, ISSN 1518-6148.

[22] SA, C. R., Carvalho, F. A. H. The problem of pharmaceutical residues in Rio Grande City. Vittalle, Rio Grande, 21 [1]: 59-72, 2009.

[23] Ueda J., et al. Environmental impact of the disposal of drugs and study of public awareness about the problem. Journal Environmental Sciences [online] Volume 5, Number 1, 2009.

[24] Bueno, C. S., Weber, D., Oliveira, K. R. Homemade Pharmacy and disposal of medicines in Luiz Fogliatto neighborhood of the city of Ijuí RS. Rev Science Pharmaceuticals Basic Appl. 30 [2]:75-82ISSN18084532, 2009.

[25] Duim, A. C. L. Disposal of drugs in the environment: the environmental problems of drug that turns waste. Philadelphia University Center. London. p. 19, 2001.

[26] Brazil, Ministry of the Environment. National Council for the Environment-CONAMA. Resolution No. 358 of 29 April 2005. It provides for the disposal of waste from health services and gives other providences. Available at: http://www.mma.gov.br/port/conama/ legiabre.cfm?codlegi=462 Accessed on 20 March 2015.

[27] IPEA. Social situation of collectors and pickers of recyclable and reusable material. Institute of Applied Economic Research - IPEA. Authors [IPEA] p. 66 in 2013. 